\title{
Erratum to: Autoradiography, MALDI-MS, and SIMS-MS Imaging in Pharmaceutical Discovery and Development
}

\author{
Eric G. Solon, ${ }^{1,3}$ Alain Schweitzer, ${ }^{2}$ Markus Stoeckli, ${ }^{2}$ and Brendan Prideaux ${ }^{2}$
}

Published online 18 December 2009

This article was published with incorrect reference citations in the permission notes in the legends for Figures 8 and 9. The permission note for Figure 8 should read: (Adapted with permission from Ref. 84). The permission note for Figure 9 should read: (Adapted with permission from Ref. 85).

\footnotetext{
${ }^{1}$ QPS, LLC, 110 Executive Drive, Suite 7, Newark, Delaware 19702, USA.

${ }^{2}$ Novartis Institutes for BioMedical Research, Basel, Switzerland.

${ }^{3}$ To whom correspondence should be addressed. (e-mail: eric.g. solon@questpharm.com)
} 